Presentación

\title{
SETENTA AÑOS DE HIJO DE LADRÓN
}

Este semestre conmemoramos la aparición de una de las principales novelas de la literatura chilena y latinoamericana: Hijo de ladrón (1951), del argentinochileno Manuel Rojas. Sin duda, así puesto, ello parece una imposición más que una elección. Y es que Rojas ha sido parte del canon de la literatura continental al menos desde que esta novela fuera publicada, seis años antes de recibir el Premio Nacional de Literatura que coronó su consagración. Se dirá entonces que esta es una obligación histórica, como tantas otras que tiene a bien celebrar la institución universitaria-lógica consecuencia de su misión patrimonialista-. Sin embargo, la presente sección se hizo espacio en esta revista con un espíritu ajeno a la celebración rutinaria de lo que las historias de la literatura y de la crítica literaria ya han sancionado como valedero. Esta sección nació de la urgencia de revisar críticamente nuestra historia literaria en relación con nuestro presente, y para hacerlo debe diferenciarse de una idea de crítica puramente anticuaria. Argumentar la vigencia de un texto supone un sondeo en el ayer, pero ante todo es prerrogativa del hoy, de un presente que desarma, reordena y/o trastoca los supuestos de la canonización histórica, con lo que transforma también nuestra visión de ese pasado.

Los estudios aquí reunidos son maneras posibles de abordar ese nudo, y para hacerlo reexaminan la novela más popular de Manuel Rojas. Hijo de ladrón continúa (re)produciéndose de maneras nuevas en sus lectores, sea esto consecuencia de su hechura retórica/estructural, que ata realismo y vanguardia; de su relación con los tiempos de la representación y del relato, que genera cierta "visión universalizada de Chile" (Aira 568); de su código ideológico, jalonado entre el anarquismo y el humanismo; de las relaciones humanas y materiales que animan su áspero y esperanzado mundo; en fin, de la experiencia que produce y que se proyecta hacia la imaginación política y cultural de su momento de producción y de nuestro presente, hacia las 
formas de hacer comunidad (y este es el problema que cruza buena parte de los textos presentados en esta ocasión). Puede que lo anterior no sea más que un parafraseo torpe de una conocida definición de Italo Calvino: "Un clásico es un libro que nunca termina de decir lo que tiene que decir" (15). La crítica literaria muestra la constitución, las frecuencias, las modalidades, los efectos y las reverberaciones de ese decir.

En un sentido más local, los estudios aquí reunidos retoman el llamado que hizo Diego Zúñiga en 2016. En "Volver a Manuel Rojas", columna publicada en la revista Qué Pasa, el escritor proponía acercarse a su literatura "por el costado [...] sin solemnidad" (s.p.), incluso al punto de esquivar Hijo de ladrón. Si esto último puede resultar algo exagerado, un golpe que intenta (justificadamente, sí) agitar las aguas de la crítica, me interesa más volver sobre el hecho fundamental que el escritor percibe: el peso de la canonización de Rojas -y yo agregaría: sobre todo, el peso político de esa canonización-. Cesare Pavese lo dijo sin ambages y con cierta dureza en la expresión: "Con los libros ocurre lo mismo que con las personas, han de tomarse en serio. Pero precisamente por ello debemos guardarnos bien de convertirlos en ídolos, es decir, en instrumentos de nuestra pereza" (279). Complementando a Calvino entonces, se podría decir que, para no monumentalizar a Rojas ni a Hijo de ladrón - para no cortarles la lengua-, vale la pena escuchar su decir en en la amplitud de su espectro y, sobre todo, aguzar el oído ante sus silencios y vacilaciones.

Desde un punto de vista de campos, esta sección no es un hecho aislado, sino que hace parte de un interés por la obra rojiana observable tanto en la academia como en el plano social más extendido. La literatura de Rojas ha regresado a las librerías y ha conocido un notable auge crítico en nuestro pasado más o menos inmediato. Al respecto, cabe destacar la activa labor de la Fundación Manuel Rojas, empujada por Jorge Guerra y Daniel Muñoz. Los textos rojianos han reaparecido en cuidados volúmenes que integran una anotación culturalista y material de archivo inédito, lo que sumado a una renovada identidad gráfica ha buscado ganar el interés del actual público lector. Ello se ha visto acompañado por la organización de numerosos conversatorios y exposiciones sobre la obra del autor, adensados en 20162017 a propósito de los 120 años de su natalicio. En un espacio limítrofe entre la difusión y el estudio de la literatura rojiana, destaca la apertura en 2019 del Archivo Manuel Rojas, a cargo de Pía Gutiérrez, María José Barros y Macarena Areco -directora del Centro de Estudios de Literatura Chilena (CELICH) de la Facultad de Letras UC, que lo conserva en comodato-. Las 
posibilidades de estudio que este archivo habilita son tan vastas como el cuerpo documental que pone a disposición del público todo.

En el terreno del estudio, el CELICH en conjunto con el CRLA-Archivos de la Universidad de Poitiers han organizado ya cuatro simposios sobre la obra de Manuel Rojas en conexión con la literatura chilena reciente (2018 y 2019). De esta experiencia han derivado dos proyectos editoriales. El primero es el libro de (una vez más) Barros y Gutiérrez, Manuel Rojas. Una oscura y radiante vida. Nuevas lecturas y aproximaciones críticas (2020), cuyos dieciocho artículos asedian desde diversas perspectivas textos clásicos del escritor y abren zonas de su obra que permanecían poco exploradas. El segundo es el número especial de Anales de Literatura Chilena dedicado a Rojas, que aparecerá en junio de este año y a cuyo cargo está Fernando Moreno. Todavía en el plano del estudio reciente, es justo reconocer la labor de Ignacio Álvarez, obstinado estudioso de la literatura de Rojas. Desde la enseñanza universitaria, la escritura de artículos y la participación en empeños editoriales, Álvarez ha construido una perspectiva sobre su obra hoy imprescindible para cualquiera que se acerque a sus textos o a su figura, perspectiva que en definitiva ha mediado la lectura del clásico para nuevas generaciones ${ }^{1}$.

En 2011 Jaime Concha afirmó que los estudios sobre Rojas se hallaban "en ciernes todavía" (244). El último hito en la historia de la crítica rojiana había sido la publicación de Manuel Rojas. Estudios críticos (2005), en que Naín Nómez y Emmanuel Tornés recogían textos escritos desde la década del treinta en adelante, haciéndose cargo de literatura crítica y testimonial de y sobre Rojas. Esos textos, que datan sobre todo de los años sesenta y setenta, dibujan los contornos de los principales problemas rojianos. En contraste, esta sección y los dos proyectos editoriales mencionados en el párrafo anterior no han necesitado retroceder mucho en el tiempo para dar con material crítico de valor, que amplía y revisa esas tesis primeras: las contribuciones que recogen no tienen más de cinco años, y algunas de ellas forman parte de proyectos de investigación en curso. ¿Han alcanzado los estudios sobre Rojas un nuevo "punto de cristalización" (Concha 244)? Mi sospecha es

Además de escribir el prologo para la tetralogia Tiempo irremediable que en 2015 reeditó Zig-Zag, Álvarez participó en la última edición, anotada y fijada con criterios filológicos, de Hijo de ladrón (Tajamar Editores, 2018). Asimismo, suya es la edición crítica de los cuentos completos de Rojas, de pronta aparición por la Editorial Universidad Alberto Hurtado. 
que sí. Parece claro el enorme interés actual en su literatura, junto con el hecho de que sus textos y su figura constituyen uno de los principales focos de la crítica en Chile ${ }^{2}$. A todo ello se suma el trabajo de edición crítica de Hijo de ladrón que hoy desarrollan David Barrera, Diego Leiva, Alejandra Caballero, Daniel Valenzuela y quien escribe. Estos diez años, pues, no han transcurrido en vano.

Los estudios que siguen son iniciados por Ignacio Álvarez, quien considera el problema de la comunidad en la novela desde su forma de plantear el vínculo social. El anclaje del lazo social en un elocuente indicio textual -la mirada de los personajes como afecto spinozista- contribuye a entender no solo una forma de producción de lo social, sino que permite a Álvarez leer la novela como una alegoría nacional del medio siglo. Le siguen dos estudios que abordan desde ángulos distintos la imaginación novelesca asociada al crimen. En un pormenorizado análisis histórico, generoso en el análisis de sus fuentes, Lorena Ubilla descubre que la novela recrea ciertas estructuras de sentimiento propias de los sectores populares. Así, el texto abre perspectivas que cuestionan las prácticas y discursos dominantes sobre la delincuencia y la sociabilidad popular a inicios del siglo XX. La nota de Diego Leiva, por su parte, indaga en las representaciones del criminal y del crimen desde lo propiamente literario: el léxico, la determinación ideológica y la producción de espacialidad. Recurriendo a abundante material genético, logra dar cuenta de la paulatina apertura que sufre la significación de aquellas. Cierra esta primera parte un estudio sobre la huella que el simbolismo masónico deja en la representación del sujeto y de la comunidad en Hijo de ladrón. La intertextualidad masónica, propongo, tensiona el plexo ético e ideológico de la novela.

2 Por otra parte, cabe preguntarse desde cuándo la literatura de Rojas y su imagen autorial se han convertido en un verdadero ícono popular en el país. Recuérdese, por ejemplo, el Centro Cultural Manuel Rojas, activo desde 2001 en el capitalino barrio Yungay. En 2015 Patricio Muñoz dirigió el documental Las cuatro vidas de Aniceto, dedicado tanto a la tetralogía como a la vida del escritor, y el mismo año se publicó la adaptación de Hijo de ladrón a novela gráfica, de la mano de Christian Morales, Luis Martínez y Marco Herrera. Todo esto habla de que la literatura de Rojas no solo sobrevivió de buena forma a su intento de adiestramiento en el aula escolar durante la dictadura de Pinochet, sino que además ahora, en los últimos estertores (¿lo serán?) de nuestra mezquina transición democrática, multiplica su valor en/desde el tejido social con renovada potencia. 
A los cuatro estudios reseñados se integra un suplemento de temática miscelánea. Grínor Rojo desarrolla las relaciones entre la serie histórica sobre cuyo fondo transcurre la acción de La oscura vida radiante y la serie biográfica de Aniceto, que allí describen la última etapa de sus respectivos ciclos. Al hacerlo, especifica cualidades que constituyen a Aniceto como héroe novelesco y repara en la drástica solución narrativa de la tetralogía. A continuación, María José Barros y Pía Gutiérrez se preguntan por el estatuto de la naturaleza en Astromelia y "El niño y el choroy", dos inéditos de Rojas. $\mathrm{Su}$ reflexión socioafectiva especifica el concepto rojiano de comunidad al comprometerlo con lo viviente en sentido amplio, además de demostrar los aportes de una lectura de Rojas que incorpore material de archivo. El último artículo es de Alejandro Fielbaum, quien aborda el problema de la política de la literatura rojiana a partir del rescate que Rojas hace de Sarmiento en su tan sonada Historia breve de la literatura chilena (1965). El valor estéticopolítico que ve en el argentino contribuye a delinear tanto al hombre de letras como al autor, pues arroja una luz filiativa que permite releer ahora su propia literatura.

Antes de cerrar, quiero agradecer a las/los autores de esta sección, por responder entusiastas a la convocatoria y acompañar el proceso editorial con la paciencia que requiere; y a los/las evaluadores(as) de estos artículos, por su rigor y generosas sugerencias. Por último, extiendo un agradecimiento aún más sentido a quienes comparten oficio con Rojas: Elena Loyola, diagramadora, y Dieter Langer, corrector de estilo, cuyo prolongado compromiso con esta revista no tambaleó ni siquiera en las circunstancias actuales, del todo anómalas y especialmente sacrificadas.

Pablo Concha Ferreccio Coordinador de la sección Setenta años de Hijo de ladrón

Universidad de Chile pabloconchas@gmail.com

\section{BIBLIOGRAFÍA}

Aira, César. "Manuel Rojas". Diccionario de autores latinoamericanos. Santiago/Madrid: Tajamar Editores/Tres Puntos Ediciones, 2018. 566-567.

Calvino, Italo. "Por qué leer los clásicos". Por qué leer los clásicos. Trad. Aurora Bernárdez. Madrid: Siruela, 2009 [1991]. 13-20. 
Concha, Jaime. "El otro tiempo perdido". Leer a contraluz. Estudios de narrativa chilena: de Blest Gana a Varas y Bolaño. Santiago: Ediciones Universidad Alberto Hurtado, 2011. 223-244.

Pavese, Cesare. "Leer". La literatura norteamericana y otros ensayos. Trad. Elcio di Fiori. Barcelona: Lumen, 2008 [1951]. 279-282.

Rubio, Cecilia. "Autobiografismo y humanismo en Manuel Rojas". Manuel Rojas: una oscura y radiante vida. Nuevas lecturas y aproximaciones críticas. Eds. María José Barros y Pía Gutiérrez. Santiago: Ediciones Universidad Católica de Chile, 2020. 45-60.

Zúñiga, Diego. "Volver a Manuel Rojas”. Qué Pasa, 20 de mayo de 2016. http://www.quepasa. cl/articulo/guia-del-ocio/2016/05/volver-a-manuel-rojas.shtml/. 